\title{
REVIEW
}

\section{Heterozygote deficiency in the mussel Mytilus edulis species complex revisited}

\author{
Michel Raymond ${ }^{1,2, *}$, Roisi L. Vääntö ${ }^{3}$, Fréderic Thomas ${ }^{4}$, François Rousset ${ }^{1}$, \\ Thierry de Meeüs ${ }^{4}$, François Renaud ${ }^{4}$
}

\author{
'Institut des Sciences de I'Evolution (UMR CNRS 5554), Laboratoire Génétique et Environnement, \\ Université de Montpellier II (CC 065), F-34095 Montpellier Cedex 05, France \\ ${ }^{2}$ Department of Genetics, Uppsala University, Box 7003, 5-75007 Uppsala, Sweden \\ ${ }^{3}$ Zoological museum, SF-00100 Helsinki, Finland
}

${ }^{4}$ Laboratoire de Parasitologie Comparée (UMR CNRS 5555), Université de Montpellier II (CC 105), F-34095 Montpellier Cedex 05, France

\begin{abstract}
In order to understand the phenomenon of heterozygote deficiency $\left(F_{i s}\right)$ in manne molluscs, all the relevant literature concerning this phenomenon in the Mytilus edulis species complex was reviewed. Due to large heterogeneity in methods of data analysis, in particular for the choice of the estimator measuring heterozygote deficiency and for the choice of the testing procedure, no clear overview was possible. To overcome this problem, similar estımators and tests were used to analyze or re-analyze some additional large data sets from the Baltic ( $M$. trossulus). France ( $M$. galloprovincialis), England (M. edulis), Atlantic USA ( $M$. edulis) and Pacific USA ( $M$. trossulus). Large and significant heterozygote deficiencies exist in these data sets. Estimated $F_{1 S}\left(F_{i s}\right)$ values are generally higher for Lap than for other loci, consistent with an effect of selection. No other significant variation of $\hat{F}_{1,}$ values across loci within each data set or across data sets for each locus was detected, however no specific test has been designed for this null hypothesis. The possible contribution of a Wahlund effect to explain the heterozygote deficiency is discussed. It is likely that there is no unique explanation of heterozygote deficiency (such as a Wahlund effect or selection) in $M$. edulis or in other organisms, and that speciesspecific, locus-specific or population-specific explanations are to be sought.
\end{abstract}

KEY WORDS: Mytilus Population genetics - Heterozygote deficiency $\cdot$ Allozyme

\section{INTRODUCTION}

Heterozygote deficiency in marine bivalves is described in a large body of literature, and several explanations have been proposed: first, a spatial or temporal Wahlund effect (Wahlund 1928) due to the incorporation of individuals from differentiated populations or cohorts in the same sample; second, a particular phenomenon at the chromosomal level, such as aneu-

- Address for correspondence: Laboratoire Génétique et Environnement, Université de Montpellier II (CC 065), F-34095 Montpellier Cedex 05, France.

E-mail: raymond@isem.univ-montp2.fr ploidy or parental imprinting; third, the presence of selection at the locus studied (or at a nearby locus in linkage disequilibrium with the marker); fourth, the frequent presence of null alleles (for reviews see e.g. Singh \& Green 1984, Zouros \& Foltz 1984, Foltz 1986, Zouros et al. 1988, Gaffney et al. 1990). Some explanations have been ruled out for a few particular species, but no consensus has emerged at present to explain heterozygote deficiencies in marine bivalves.

The phenomenon of heterozygote deficiency in marine bivalves was described for the first time in the mussel Mytilus edulis, and concerned only 1 locus (Lap) (Milkman \& Beaty 1970), in a geographic location where strong selection occurs for this locus and generates heterozygote deficiency each generation (Koehn 
et al. 1980, Koehn \& Immermann 1981, Koehn \& Siebenaller 1981, Hilbish et al. 1982, Hilbish 1985, Hilbish \& Koehn 1985). Studies have since then been expanded to other loci, other populations and other bivalve species, and, apparently, heterozygote deficiency is a widespread phenomenon in this group of marine organisms (Singh \& Green 1.984, Zouros \& Foltz 1984).

Mytilus edulis has remained one of the few species thoroughly studied for the problem of heterozygote deficiency. The taxonomy and the various members of this species complex have been studied (the $M$. edulis species complex contains 3 members: $M$. edulis, $M$. trossulus and $M$. galloprovincialis). The locations of hybrid or contact zones or secondary intergradation are relatively well known in some areas (e. g. Skibinski et al. 1978, 1983, Skibinski \& Beardmore 1979, Skibinski 1983, Varvio et al. 1988, Coustau et al. 1991, Koehn 1991, MCDonald et al. 1991, Väinölä \& Hvilsom 1991, Sarver \& Foltz 1993, Sanjuan et al. 1994, Bates \& Innes 1995, Quesada et al. 1995a, b, Rawson \& Hilbish 1995). Hence, reports of heterozygote deficiency from such areas can be assigned to a Wahlund effect. These mussels are also studied for reasons other than heterozygote deficiency, so that independent data sets are available to circumvent a possible publication bias.

From the large amount of information published on this particular species, is it possible to draw general conclusions on the significance of heterozygote deficiency? The purpose of this paper is to review the accessible data concerning heterozygote deficiency in the Mytilus edulis complex. Due to large heterogeneities in methods of data analysis, in particular for the choice of the estimator measuring heterozygote deficiency and for the choice of the testing procedure, no clear overview was possible. To overcome this problem, similar estimators and tests were used to analyze or re-analyze some large data sets.

\section{MATERIALS AND METHODS}

Revisiting the Mytilus edulis literature. The 26 years of publication on heterozygote deficiency in the Mytilus edulis complex were divided for convenience into 2 periods, from the beginning (1970) to 1984, and from 1985 to the latest papers (1996). Two review articles from 1984 (Singh \& Green 1984, Zouros \& Foltz 1984 ) ensure that no old papers were overlooked. A literature search on accessible databases was performed for recent publications, but some papers may have remained unnoticed. All papers which display a measure or a test of heterozygote deficiency in at least 1 sample from a natural population were retained for further examination. However, papers devoted to the study of hybrid zones were not considered, unless pure populations were also studied (e.g as in Skibinski et al. 1983).

Data sets. Altogether 5 data sets were analyzed or re-analyzed. The first was a Baltic data set from an MSc thesis (Väinölä 1985). Eighteen samples from the northern part of the basin (Finland and Estonia), all located at least $750 \mathrm{~km}$ from the Öresund hybrid zone (Väinölä \& Hvilsom 1991), were selected for analysis from a larger data set. Genotypes of a maximum of 3031 Mytilus trossulus mussels were available at 4 loci (Lap, Ap, Pgi and Idh). The second was a French data set from a university report by F.T. (Thomas 1993) which consisted of 6 samples of $M$. galloprovincialis from the Mediterranean (Languedoc-Roussillon) and the Atlantic (Basque area). One of the Atlantic samples (Vieux Boucaux) was removed on the grounds that it was too close to a M. edulis/galloprovincialis hybrid zone (Coustau et al. 1991. Sanjuan et al. 1994) leaving only 5 samples in the data set. Genotypes of a maximum of $143 \mathrm{M}$. galloprovincialis mussels were available for 7 loci (Lap, Pgi, PepA, Pep-D, Mpi and Est-D). The third was an English data set published by Ahmad \& Hedrick (1985) for studies of linkage disequilibrium. Two samples of $1000 \mathrm{M}$. edulis each were analyzed for 4 loci. Detailed genotypes at both $L a p$ and $A p$ were available for further analyses. The fourth was an Atlantic American data set of $M$. edulis analyzed by Koehn \& Gaffney (1984) and kindly provided by P. M. Gaffney upon request. This data set consists of 1 sample of 8 size classes of the same age analyzed at 5 loci ( $L a p, A p$, Pgm, Odh, Pgi). Although heterozygote deficiency was measured (but not tested) in their paper, the purpose of Koehn \& Gaffney's work was to analyze the growth/heterozygosity relationship of $M$. edulis, not heterozygote deficiency. The fifth was a Pacific American data set published by Johnson \& Utter (1973) for the study of the genetics of 1 electrophoretic locus (aspartate amino transferase, or Aat). Six samples representing 644 individuals were analyzed at 1 locus (Aat), The correct scientific name is certainly $M$. trossulus, and not $M$. edulis as stated by the authors (see e.g. McDonald et al. 1991).

Statistics. Hardy-Weinberg equilibrium (HWE) was tested using the exact $U$-score test of Rousset \& Raymond (1995), when the alternative hypothesis $\left(H_{1}\right)$ is heterozygote deficiency. This test has several advantages. First, it is an exact test, so that low sample size or low allelic frequency is not a problem (in contrast to tests based on asymptotic distributions). Second, the power of this test (when $H_{1}$ is true) is close to the maximum possible. Third, this test can be readily extended to multiple samples, the null hypothesis becoming 'random association of gametes in each sample' (Rous- 
set \& Raymond 1995). A complete enumeration algorithm (Louis \& Dempster 1987) was used whenever possible to compute exact p-values, or a Markov chain method (Guo \& Thompson 1992) was used for their unbiased estimates. In such cases, chains were at least 20000 steps long (up to 100000 when greater precision was needed), with 1000 steps of dememorization (see Guo \& Thompson 1992 for details). Heterozygote deficiency $F_{1 S}$ was measured using either the $F_{i s}$ estimator $f_{c}$ of Weir \& Cockerham (1984) or $f_{T}$ of Robertson \& Hill (1984). The latter has a minimum variance when $F_{i s}=0$ and is also monotonously related to the statistics used to define the rejection zone of the exact $U$-score test (see Rousset \& Raymond 1995). The former could easily be extended to have global $F_{\text {is }}$ estimates. For all these computations (tests and measures), the Genepop (version 2.0) software was used (Raymond \& Rousset 1995)

\section{RESULTS}

\section{Revisiting the Mytilus-edulis-complex literature}

A total of 20 papers were analyzed. The occurrence of significant heterozygote deficiency in the moststudied loci (Table 1) is considered first. All studies except 1 (which is devoted to the genetics of the locus Aat) include the locus Lap. Due to the strong selection acting at this locus in some geographic areas, Lap has been analyzed separately. The 3 most widely analyzed loci are Pgm, Odh and Pgi. Significant and non-significant departures from HardyWeinberg equilibrium are reported for these 3 loci in Table 1, although it is difficult to extract an overall picture due to the variety of situations and approaches used. A more detailed analysis on this body of literature is needed.

Table 1. Literature from (A) 1970 to 1984 and (B) 1985 to 1996 consulted on heterozygote deficiency in the Mytilus edulis complex. Country where mussels were sampled, the number of samples analyzed and the number of loci examined are indicated. For the 3 most studied loci, Pgm, Odh and Pgi (Lap is excluded, see text), the signuficance level (Hardy-Weinberg; ns: $\mathrm{p}>0.05 ; \cdot \mathrm{p}<$ $0.05 ; \cdots p<0.01 ; \cdots p<0.001$ ) of the test of heterozygote deficiency, as reported by the authors, is indicated. (?) indicates the result of the test was not clear; (-) indicates the locus was not examined

\begin{tabular}{|c|c|c|c|c|c|c|}
\hline Country & Samples & No. of locl & Pgm & $\begin{array}{c}\text { Locus } \\
\text { Odh }\end{array}$ & Pgi & Source \\
\hline \multicolumn{7}{|l|}{ (A) $1970-1984$} \\
\hline USA & 24 & 1 & $=$ & - & - & Milkman \& Beaty (1970) \\
\hline USA & 4 & 2 & - & - & - & Koehn \& Mitton (1972) \\
\hline USA & 12 & 2 & - & - & - & Mitton et al. (1973) \\
\hline USA & 6 & 1 & - & - & - & Johnson \& Utter (1973) \\
\hline USA & 16 & 1 & - & - & - & Boyer (1974) \\
\hline USA & 150 & 6 & - & - & ns & Koehn et al. (1976) \\
\hline USA & 18 & 1 & - & - & - & Lassen \& Turano (1978) \\
\hline UK & 68 & 11 & $?^{a}$ & - & $?^{\mathrm{a}}$ & Skibinski et al. (1983) \\
\hline USA & 8 & 5 & $?^{b}$ & $?^{b}$ & $?^{b}$ & Koehn \& Gaffney (1984) \\
\hline \multicolumn{7}{|l|}{ (B) $1985-1996$} \\
\hline USA & 3 & 5 & $?^{c}$ & $?^{x}$ & $?^{\mathrm{c}}$ & Diehl et al. (1985) \\
\hline Ireland & 3 & 4 & - & & ns & Gosling \& Wilkins (1985) \\
\hline Norway & 13 & 30 & ns & ns & ns & Fevolden \& Garner (1986) \\
\hline USA & 1 & 7 & “ & ns & $\cdots$ & Zouros et al. (1988) \\
\hline UK & 1 & 8 & a & d & a & Gentili \& Beaumont (1988) \\
\hline Ireland & 1 & 5 & $\cdot d$ & e & - & Gosling (1989) \\
\hline Spain & 9 & 4 & - & $\cdot 1$ & - & Sanjuan et al. (1990) \\
\hline USA & 6 & 5 & $?^{\mathrm{b}}$ & $?^{\mathrm{b}}$ & $?^{\mathrm{b}}$ & Gaffney $(1990)$ \\
\hline Iberian Peninsula & 37 & 5 & - & $\cdot 9$ & - & Sanjuan et al. (1994) \\
\hline UK & 1 & 6 & $\because$ & ns & ns & Fairbrother \& Beaumont (1993) \\
\hline Iberian Peninsula & & & $?^{n}$ & $?^{h}$ & $\cdot 1$ & Quesada et al. (1995b) \\
\hline \multicolumn{7}{|c|}{${ }^{a}$ Test provided only for each allele } \\
\hline \multicolumn{7}{|c|}{${ }^{b}$ Hardy-Weinberg not tested } \\
\hline \multicolumn{7}{|c|}{ 'Test not indicated; $p$-values not given } \\
\hline \multicolumn{7}{|c|}{${ }^{\mathrm{d}}$ For both size classes } \\
\hline \multirow{2}{*}{\multicolumn{7}{|c|}{$\begin{array}{l}{ }^{e} p<0.001 \text { for small size classes, and not significant for large size classes } \\
\text { ' Significant deficiency in } 3 \text { out of } 5 \text { samples }\end{array}$}} \\
\hline & & & & & & \\
\hline \multicolumn{7}{|c|}{ gSignificant deficiency in half of the samples } \\
\hline \multicolumn{7}{|c|}{ Details not given for samples outside the intergradation cline } \\
\hline${ }^{1}$ For samples outsid & the inters & ation zone, 2 & ignific & fter B & nio & \\
\hline
\end{tabular}


How was heterozygote deficiency measured?

Except for a few studies where heterozygote deficiency was not measured, 3 different measures are used: $D, f_{c}$ and $f_{T}$ (Table 2). $D$ (or $-D$ ) is defined as $1-$ $H_{0} / H_{e}$, where $H_{0}$ is the observed frequency of heterozygotes, and $H_{e}$ is $1-\sum p_{j}^{2}$ ( $p_{j}$ being the observed frequency of allele $j$ in the sample). $H_{e}$ is often designated (incorrectly, see Levene 1949) as the expected frequency of heterozygotes under HWE. $f_{c}$ is the $F_{1 s}$ estimator defined by Weir \& Cockerham (1984), and $f_{T}$ is the $F_{i s}$ estimator defined by Robertson \& Hill (1984). The first measure is used in the majority of the studies, while the other 2 seem to be used only in recent publications (Table 2).

How was heterozygote deficiency tested?

Except for 6 studies in which no test of Hardy-Weinberg equilibrium is apparent, several types of test are used in the literature analyzed (Table 3). For asymptotic $\mathrm{X}^{2}$ goodness of fit tests, which compare observed and 'expected' genotype counts, 2 different tests can be performed, depending on whether all genotypic classes $\left(X^{2}-g\right.$ test) or only 2 classes (homozygotes vs heterozygotes, $X^{2}$-h test) are considered. Another test, the asymptotic test proposed by Brown (1970), uses $\hat{F}_{\text {, }}$ the maximum likelihood estimator of $F_{i s}$ for 2-allele cases $\left(\mathrm{X}^{2}-2\right.$ test). This test is a particular case of the test proposed by Li \& Horvitz (1953) and Equation 1 of Brown (1970), where the variance of $\hat{F}$ is $1 / n$ (n being the sample size), is always used. A third test is the asymptotic test described by Robertson \& Hill (1984) ( $f_{r}$-test). In addition miscellaneous tests which are not clearly described in the original publications are also used (see Table 3). The $\mathrm{X}^{2}-\mathrm{g}$ and $\mathrm{X}^{2}-2$ tests are widely used, and the others are used in only $1\left(X^{2}-h\right)$ or few studies.

\section{Studying heterozygote deficiency in 'independent' data sets}

\section{Baltic data set}

The genotype of about 3000 mussels for the Lap. Ap and Pgi loci and of more than 1000 mussels for the $I d h$ locus are analyzed. The mean sample size is 159 mussels, varying from a minimum of 64 to a maximum of 306. Measures of heterozygote departure from HardyWeinberg equilibrium are shown in Table 4. Multipopulation estimated heterozygote deficiencies are positive for all loci, indicating some heterozygote deficiency, which is apparently higher for Lap. The overall estimate across all populations and all loci is positive and low when Lap is excluded.

Table 2. Measures of heterozygote deficiency in the Mytilus edulis complex used in the literature. Whether global estimates of $F_{1:}$ across loci or populations have been used is indicated. See 'Results' for further explanation

\begin{tabular}{|c|c|c|c|c|c|c|c|}
\hline & $1-H_{0} / H_{e}$ & $f_{c}$ & $f_{T}$ & None & Not indicated & Global estimates & Source \\
\hline \multicolumn{8}{|l|}{ (A) $1970-1984$} \\
\hline & & & & & $\mathrm{x}$ & No & Milkman \& Beaty $(1970)$ \\
\hline & & & & $\mathrm{x}$ & & No & Koehn \& Mitton (1972) \\
\hline & & & & $\mathrm{x}$ & & No & Johnson \& Utter (1973) \\
\hline & & & & $\mathrm{x}$ & & No & Mitton et al. (1973) \\
\hline & $x$ & & & & & No & Boyer $(1.974)$ \\
\hline & $\mathrm{x}$ & & & & & Yes & Koehn et al. (1976) \\
\hline & $\mathrm{x}$ & & & & & No & Lassen \& Turano (1978) \\
\hline & $\mathrm{x}$ & & & & & Yes & Skibinski et al. (1983) \\
\hline & $\mathrm{x}$ & & & & & Yes & Koehn \& Gaffney (1984) \\
\hline \multicolumn{8}{|l|}{ (B) 1985-1996 } \\
\hline & $\mathrm{x}$ & & & & & Yes $^{a}$ & Gosling \& Wilkins (1985) \\
\hline & $\mathrm{x}$ & & & & & No & Diehl et al. (1985) \\
\hline & $\mathrm{x}$ & & & & & No & Zouros et al. (1988) \\
\hline & & & & & $x^{h}$ & Yes & Gentilı \& Beaumont (1988) \\
\hline & & & & $x$ & & No & Fevolden \& Garner (1986) \\
\hline & $\mathrm{x}$ & & & & & No & Gosling (1989) \\
\hline & & $\mathrm{x}$ & $\mathrm{x}$ & & & Yes & Sanjuan et al. (1990) \\
\hline & $x$ & & & & & No & Gaffney $(1990)$ \\
\hline & $x$ & & & & & No & Fairbrother \& Beaumont (1993) \\
\hline & & $\mathrm{x}$ & $x$ & & & Yes & Sanjuan et al. (1994) \\
\hline & & & $x$ & & & No & Quesada et al. (1995b) \\
\hline
\end{tabular}


Across populations, $F_{i s}$ estimates were significantly non-randomly ranked for each. locus (Kendall test of concordance, $p<10^{-5}$, first line of Table 5), suggesting that loci are subject to similar phenomena within each population. However, this trend was due to the high $F_{\text {is }}$ value for Lap, as no significant ( $p>0.3$ ) effect was apparent when Lap was removed (Table 5). The median $\hat{F}_{\text {is }}$ value was not different for each locus (Kruskal-Wallis ANOVA by rank, $\mathrm{X}^{2}=1.78, \mathrm{df}=3, \mathrm{p}=$ $0.62)$, except when Lap was also considered $\left(\mathrm{X}^{2}=20.3\right.$, $\mathrm{df}=3, \mathrm{p}=0.0001$ ).

Tests indicate an overall significant heterozygote deficiency, even when the Lap locus is removed from the data set (Table 6). Of the 4 loci, 3 were individually significant, although $A p$ displayed a marginally significant level. Hardy-Weinberg equilibrium cannot be rejected for $I d h$ in this data set.

\section{French data set}

The genotypes of about 143 mussels for 7 loci ( $L a p$, Idh, Pgi, PepA, Pep-D, Mpi and Est-D) are analyzed. The mean sample size is 24 mussels, varying from a minimum of 19 to a maximum of 35 . Measures of heterozygote departure from Hardy-Weinberg equilibrium are shown in Table 7 . Multi-population $\hat{F}_{i s}$ are positive for all loci except Pep-A and $M p i$, indicating some heterozygote deficiency, which is apparently higher for Est-D and Idh. The overall estimate across all populations and all loci is positive. Across populations, $\hat{F}_{i s}$ was ranked randomly for each locus (Kendall test of concordance, $p>0.20$, second line of Table 5), and the median $\hat{F}_{I S}$ value was not different for each locus (Kruskal-Wallis ANOVA by rank, $\mathrm{X}^{2}=7.0, \mathrm{df}=6$, $\mathrm{p}=0.321$ ).

Table 5. Measure and test of random ranking of $\hat{F}_{i s}$ across populations for the various loci studied in each data set. The Kendall coefficient of concordance ( $W$ ) and the corresponding p-value, computed according to Siegel \& Castellan (1988), are indicated. Results are presented for all loci including and excluding Lap. A global test (Fisher's method) across data sets (All) is computed according to Fisher (1970). Bold characters indicate significant $(p<0.05) p$-values

\begin{tabular}{|c|c|c|c|c|}
\hline \multirow[t]{2}{*}{ Data set } & \multicolumn{2}{|c|}{ Lap included } & \multicolumn{2}{|c|}{ Lap excluded } \\
\hline & W & $\mathrm{p}$ & W & $\mathrm{p}$ \\
\hline Baltic & 0.676 & $<10^{-5}$ & 0.049 & 0.346 \\
\hline French & 0.259 & 0.262 & 0.272 & 0.245 \\
\hline English & 1.000 & 0.083 & - & - \\
\hline Atlantic USA & 0.297 & $<0.05$ & 0.262 & 0.098 \\
\hline Pacific USA & - & - & - & - \\
\hline All & - & $<10^{-4}$ & - & 0.143 \\
\hline
\end{tabular}

Table 6. Testing heterozygote deficiency for the Baltic data set. Exact p-values are indicated for each locus in edch sample. Unbiased estimates of exact $p$-values of the U-score test (Markov chain of 20000 steps for Lap, Pgi and Idh, and of 100000 steps for $A p$ ) are given for global tests (All). All - Lap indicates that the Lap locus has been excluded for this multilocus test. Bold characters indicate significant $(p<0.05)$ probabilities

\begin{tabular}{|c|c|c|c|c|c|c|}
\hline Pop & Lap & $A p$ & $P g i$ & $I d h$ & All & All - Lap \\
\hline 1 & $10^{-4}$ & 0.930 & 1 & 1 & 0.131 & 0.989 \\
\hline 2 & 0.001 & 0.004 & 1 & 0.302 & 0.003 & 0.044 \\
\hline 3 & 0.229 & 0.183 & 1 & 0.855 & 0.237 & 0.271 \\
\hline 4 & 0.011 & 0.679 & 0.131 & 0.584 & 0.029 & 0.220 \\
\hline 5 & 0.001 & 0.443 & 0.267 & 0.636 & 0.016 & 0.240 \\
\hline 6 & 0.001 & 0.262 & 1 & - & 0.019 & 0.336 \\
\hline 7 & 0.006 & 0.091 & 1 & - & 0.032 & 0.202 \\
\hline 8 & 0.013 & 0.088 & 0.058 & - & 0.004 & 0.009 \\
\hline 9 & 0.084 & 0.717 & 1 & - & 0.420 & 0.730 \\
\hline 10 & 0.003 & 0.790 & 1 & 0.918 & 0.255 & 0.937 \\
\hline 11 & 0.004 & 0.851 & 0.001 & 0.258 & $<10^{-4}$ & 0.001 \\
\hline 12 & 0.003 & 0.008 & 0.093 & - & 0.001 & 0.008 \\
\hline 13 & 0.016 & 0.517 & 0.201 & - & 0.075 & 0.293 \\
\hline 14 & 0.002 & 0.315 & 1 & 0.268 & 0.056 & 0.405 \\
\hline 15 & 0.358 & 1 & 1 & - & 0.760 & 0.974 \\
\hline 16 & 0.001 & 0.223 & 0.111 & 0.699 & 0.005 & 0.120 \\
\hline 17 & 0.222 & 0.581 & 1 & - & 0.521 & 0.783 \\
\hline 18 & 0.075 & 0.331 & 0.739 & 0.431 & 0.230 & 0.453 \\
\hline All: & $<10^{-4}$ & $0.050^{\alpha}$ & 0.016 & 0.451 & $<10^{-4}$ & 0.003 \\
\hline \multicolumn{7}{|c|}{$\begin{array}{l}\text { A chain of } 100000 \text { steps was run for a better precision } \\
\text { in this particular case, resulting in a standard error of } \\
\text { the p-value of } 0.002\end{array}$} \\
\hline
\end{tabular}

Significant $(p<0.05)$ heterozygote deficiency is found for 3 loci (Est-D, Idh and Pgi) out of 7 (Table 8), and over all loci this deficiency is highly significant $(\mathrm{p}=$ $0.0029)$

\section{English data set}

Ahmad \& Hedrick (1985) presented genotypic data for 1000 mussels at 2 loci (Lap and $A p$ ), in 2 populations. For the Lap locus, the measure of heterozygote deficiency is close to +0.1 , and tests within each population or for both are highly significant (Table 9). For the Ap locus, the measure of heterozygote deficiency is lower and its sign is not congruent for both estimators, although the overall estimate is positive. Across populations, $\hat{F}_{15}$ was ranked randomly for each locus (Kendall test of concordance, $p>0.05$, third line of Table 5), and the median $\hat{F}_{15}$ value was different between both loci (Kruskal-Wallis ANOVA by rank, $\mathrm{X}^{2}=$ $6.0, \mathrm{df}=1, \mathrm{p}=0.0143)$. A significant deficiency $(\mathrm{p}<$ $0.05)$ is detected for the first population but not for the second ( $p>0.5)$, and the overall test is not significant, although it is close to the significance level (Table 9). 
Table 7. Measures of heterozygote deficiency for the French data set (2 Mediterranean and 3 Atlantic populations). Weir \& Cockerham (1984) and Robertson \& Hill (1984) estimators of $F_{t s}$ are given for each locus and each sample (respectively $f_{C}$ and $f_{T}$ ). Estimates for all loci in each sample, for all samples for each locus, and for all samples and all loci are given (All)

\begin{tabular}{|c|c|c|c|c|c|c|c|c|c|c|c|c|c|c|c|}
\hline \multirow[t]{2}{*}{ Sample } & \multicolumn{2}{|c|}{ Pep-A } & \multicolumn{2}{|c|}{ Est-D } & \multicolumn{2}{|c|}{ Lap } & \multicolumn{2}{|c|}{$I d h$} & \multicolumn{2}{|c|}{$M p i$} & \multicolumn{2}{|c|}{$P e p-D$} & \multicolumn{2}{|r|}{$P g i$} & \multirow{2}{*}{$\begin{array}{l}\text { All } \\
f_{c}\end{array}$} \\
\hline & $f_{c}$ & $f_{T}$ & $f_{c}$ & $f_{T}$ & $f_{c}$ & $f_{T}$ & $f_{c}$ & $f_{T}$ & $f_{\mathrm{r}}$ & $f_{T}$ & $f_{c}$ & $f_{T}$ & $f_{c}$ & $f_{T}$ & \\
\hline \multicolumn{16}{|c|}{ Mediterranean } \\
\hline $1-$ & -0.014 & +0.010 & -0.030 & -0.016 & +0.160 & +0.142 & +0.366 & +0.374 & -0.065 & -0.065 & -0.050 & -0.003 & -0.045 & +0.110 & +0.027 \\
\hline 2 & -0.280 & -0.188 & +0.654 & +0.684 & +0.074 & +0.047 & -0.059 & -0.060 & -0.027 & -0.028 & +0.308 & +0.129 & -0.041 & -0.042 & +0.030 \\
\hline \multicolumn{16}{|c|}{ Atlantic } \\
\hline $3+$ & +0.022 & -0.004 & +0.079 & -0.027 & +0.124 & +0.045 & +0.251 & +0.256 & -0.100 & -0.101 & - & - & +0.131 & +0.028 & +0.094 \\
\hline 4 & +0.123 & +0.092 & +0.341 & +0.370 & -0.055 & -0.017 & +0.081 & +0.082 & -0.070 & -0.023 & -0.052 & +0.100 & -0.037 & +0.008 & +0.033 \\
\hline 5 & -0.169 & -0.124 & -0.098 & -0.050 & +0.048 & +0.009 & +0.384 & +0.398 & +0.143 & -0.003 & -0.143 & -0.064 & +0.315 & +0.188 & +0.079 \\
\hline All & -0.025 & & +0.183 & & +0.076 & & +0.228 & & -0.033 & & +0.003 & & +0.065 & & +0.050 \\
\hline
\end{tabular}

Table 8. Testing heterozygote deficiency for the French data set. Exact p-values are indicated for each locus in each sample. Unbiased estimates of exact p-values of the $U$-score test (Markov chain of 50000 steps) are given for global tests (All). Bold characters indicate significant ( $\mathrm{p}<$ 0.05) probabilities

\begin{tabular}{|lcccccccc|}
\hline \multicolumn{2}{l}{ Sample Pep-A } & Est-D & Lap & Idh & Mpi & Pep-D & Pgi & All \\
\hline \multicolumn{2}{l}{ Mediterranean } & & & & & & & \\
1 & 0.428 & 1 & 0.132 & 0.142 & 1 & 0.468 & 0.109 & 0.065 \\
2 & 0.908 & $<2 \times \mathbf{1 0}^{-5}$ & 0.479 & 1 & 1 & 0.097 & 0.777 & 0.211 \\
Atlantic & & & & & & & & \\
3 & 0.469 & 0.298 & 0.271 & 0.190 & 1 & - & 0.332 & 0.232 \\
4 & 0.115 & $\mathbf{0 . 0 2 6}$ & 0.661 & 0.526 & 1 & 0.106 & 0.422 & $\mathbf{0 . 0 1 7}$ \\
5 & 0.896 & 1 & 0.433 & 0.125 & 0.259 & 1 & $\mathbf{0 . 0 2 1}$ & 0.150 \\
All & 0.628 & $\mathbf{0 . 0 2 7}$ & 0.148 & $\mathbf{0 . 0 1 1}$ & 0.631 & 0.180 & $\mathbf{0 . 0 2 2}$ & $\mathbf{0 . 0 0 3}$ \\
\hline
\end{tabular}

\section{Pacific American data set}

Out of 6 samples, 4 display a high $\left(f_{t}\right.$ or $f_{c}>$ 0.09 ) and significant $(p<0.02)$ deficiency of heterozygotes (Table 12). A slight heterozygote excess is displayed by 1 sample, and for another there is either an excess or a deficiency depending of the estimator used. No significant ( $p>0.06$ ) heterozygote deficiency is found in these 2 samples. Overall, there is a high $\left(f_{c}=0.162\right)$ and significant $\left(\mathrm{p}<5 \times 10^{-5}\right)$ deficiency of heterozygotes (Table 12 ).

Some loci are studied in more than 1 data set, so that a comparative analysis is possible. For each locus, the median of the distribution of $\hat{F}_{i s}$ is not different across data sets (Kruskal-Wallis 1-way ANOVA, Lap: $\mathrm{X}^{2}=$

Atlantic American data set

The unique 1 cohort sample analyzed by Koehn \& Gaffney (1984) is divided into 8 size classes. Measures of heterozygote deficiency are shown Table 10 and indicate a relatively high deficiency (overall estimate: +0.128 ), confirming their previous claim. The negative correlation between the measure of heterozygote deficiency and size class is confirmed using Weir \& Cockerham's estimator (Kendall correlation $=-0.762, \mathrm{n}=8$, $\mathrm{p}<0.05) . \hat{F}_{l s}$ was not randomly ranked across size classes for each loci (Kendall test of concordance, $\mathrm{p}<$ 0.05, Table 5), although this effect disappeared when Lap was removed (Kendall test of concordance, $\mathrm{p}>0.1$, fourth line of Table 5). The median $\hat{F}_{\text {IS }}$ value was not different for each locus (Kruskal-Wallis ANOVA by rank, $X^{2}=3.0, \mathrm{df}=4, \mathrm{p}=0.558$ ), except when Lap was also considered $\left(X^{2}=11.0, d f=4, p=0.0266\right)$. HardyWeinberg equilibrium was rejected (due to significant heterozygote deficiency) for all loci except $A p$ (Table 11).
6.19, df $=3, p=0.103$, Baltic, French, English, Atlantic USA data sets; $A p: \mathrm{X}^{2}=3.42, \mathrm{df}=3, \mathrm{p}=0.331$, Baltic, French, English, Atlantic USA data sets; Pgi: $\mathrm{X}^{2}=3.06$,

Table 9. Measures and tests of heterozygote deficiency for the English data set (2 populations). Weir \& Cockerham (1984) and Robertson \& Hill (1984) estimators of $F_{i s}$ are given for each locus and each sample (respectively $f_{\mathrm{C}}$ and $f_{T}$ ). Estimates for all samples for each locus are given ('All'). Unbiased estimates of exact p-values of the U-score test (Markov chain of 200000 steps for each locus in each sample and of 100000 steps for multi-sample tests) are also given (test). Bold characters indicate significant $(p<0.05)$ results

\begin{tabular}{|lllllll|}
\hline Sample & \multicolumn{2}{c}{ Lap } & Test & \multicolumn{2}{c}{$A p$} & Test \\
& $f_{c}$ & $f_{f}$ & & $f_{c}$ & $f_{T}$ & \\
\hline Pendine & +0.076 & +0.077 & $<5 \times \mathbf{1 0}^{-\mathbf{6}}$ & +0.017 & +0.036 & $\mathbf{0 . 0 2 7}$ \\
Aberavon & $+0.109+0.051$ & $\mathbf{0 . 0 0 1}$ & +0.037 & -0.002 & 0.518 \\
All & +0.092 & & $<\mathbf{1 0 ^ { - 5 }}$ & +0.027 & & 0.060 \\
\hline
\end{tabular}


Table 10. Measures of heterozygote deficiency for the Atlantic American data set (1 cohort, 8 size classes). Weir \& Cockerham (1984) and Robertson \& Hill (1984) estimators of $F_{1}$ are given for each locus and each sample (respectively $f_{c}$ and $f_{T}$ ). Estimates for all loci in each samples, for all samples for in each locus, and for all samples and all loci are given (All)

\begin{tabular}{|c|c|c|c|c|c|c|c|c|c|c|c|}
\hline \multirow{2}{*}{$\begin{array}{l}\text { Size class } \\
(\mathrm{mm})\end{array}$} & \multicolumn{2}{|c|}{$L a p$} & \multicolumn{2}{|c|}{$A p$} & \multicolumn{2}{|c|}{ Pgm } & \multicolumn{2}{|c|}{ Odh } & \multicolumn{2}{|c|}{ Pgi } & \multirow{2}{*}{$\begin{array}{c}\text { All } \\
f_{c}\end{array}$} \\
\hline & $f_{c}$ & $f_{T}$ & $f_{c}$ & $f_{T}$ & $t_{c}$ & $f_{T}$ & $f_{c}$ & $f_{T}$ & $f_{c}$ & $f_{T}$ & \\
\hline $4-6$ & +0.327 & +0.302 & +0.103 & +0.087 & +0.466 & +0.564 & -0.040 & -0.024 & +0.157 & +0.107 & +0.235 \\
\hline $6-8$ & +0.160 & +0.124 & +0.074 & +0.055 & +0.517 & +0.383 & -0.054 & -0.030 & +0.073 & -0.011 & +0.148 \\
\hline $8-10$ & +0.199 & +0.202 & +0.077 & +0.068 & +0.298 & +0.306 & +0.358 & +0.136 & +0.120 & +0.079 & +0.180 \\
\hline $10-12$ & +0.227 & +0.208 & -0.071 & -0.104 & -0.002 & +0.002 & +0.225 & +0.098 & +0.334 & +0.244 & +0.157 \\
\hline $12-1.4$ & +0.042 & -0.011 & -0.014 & -0.018 & -0.013 & -0.030 & +0.194 & +0.040 & +0.010 & +0.011 & +0.025 \\
\hline $14-16$ & +0.130 & +0.044 & -0.036 & -0.010 & +0.193 & +0.160 & +0.069 & +0.043 & +0.050 & +0.038 & +0.065 \\
\hline $16-18$ & +0.122 & +0.110 & -0.006 & -0.015 & +0.175 & +0.093 & +0.132 & +0.089 & +0.113 & +0.028 & +0.096 \\
\hline $18-20$ & -0.032 & -0.051 & +0.094 & +0.091 & +0.030 & +0.056 & +0.444 & +0.265 & -0.065 & -0.079 & +0.061 \\
\hline All & +0.158 & & +0.026 & & +0.236 & & +0.195 & & +0.114 & & +0.128 \\
\hline
\end{tabular}

Table 11 Testing heterozygote deficiency for the Atlantic American data set. Unbiased estimates of exact p-values of the $U$-score test (Markov chain of 100000 steps for each locus in each sample and of 50000 steps for multi-sample tests) are given. Bold characters indicate significant $(p<0.05)$ probabilities

\begin{tabular}{|c|c|c|c|c|c|c|}
\hline $\begin{array}{l}\text { Size class } \\
(\mathrm{mm})\end{array}$ & s Lap & $A p$ & $P g m$ & Odh & Pgi & Alt \\
\hline $4-6$ & 0.001 & 0.135 & $<10^{-5}$ & 1. & \multicolumn{2}{|c|}{$0.045<2 \times 10^{-5}$} \\
\hline $6-8$ & 0.057 & 0.238 & $10^{-4}$ & 1. & 0.554 & 0.006 \\
\hline $8-10$ & 0.005 & 0.188 & 0.002 & 0.056 & \multicolumn{2}{|c|}{$0.111<2 \times 10^{-5}$} \\
\hline $10-12$ & 0.006 & 0.913 & 0.610 & 0.076 & 0.001 & 0.003 \\
\hline $12-14$ & 0.533 & 0.570 & 0.639 & 0.190 & 0.429 & 0.475 \\
\hline $14-16$ & 0.296 & 0.555 & 0.030 & 0.378 & 0.280 & 0.053 \\
\hline $16-18$ & 0.071 & 0.598 & 0.114 & 0.137 & 0.319 & 0.036 \\
\hline $18-20$ & 0.702 & 0.164 & 0.305 & 0.035 & 0.806 & 0.197 \\
\hline All & $<2 \times 10^{-5}$ & \multicolumn{3}{|c|}{$0.261<2 \times 10^{-5} 0.019$} & \multicolumn{2}{|c|}{$0.004<2 \times 10^{-5}$} \\
\hline
\end{tabular}

df $=2, p=0.216$, Baltic, French, Atlantic USA data sets; Idh: $\mathrm{X}^{2}=0.379, \mathrm{df}=1, \mathrm{p}=0.538$, Baltic, French data sets).

\section{DISCUSSION}

The subject of heterozygote deficiency in marine bivalves has attracted a large number of investigations, although no consensus exists among workers in this area. The number of species considered, the different statistical tools used, and the variety of geographical areas sampled and loci analyzed do not facilitate the comparison of the numerous papers on the subject. Even when only 1 species is considered (here the species complex Mytilus edulis), it is difficult to appreciate whether or not there is a general trend for heterozygote deficiency due to large variety in methods of data analysis (e.g. Table 1). Re-analysing pub- lished data is rarely possible because genotypic data are seldom available. This aspect is problematic in population genetics, as better estimators and more adequate statistical tests are continuously appearing in the literature. For example, adequate estimators (at least understandable definitions) of departure from Hardy-Weinberg proportions, such as $f_{C}$ or $f_{T}$ (Robertson \& Hill 1984, Weir \& Cockerham 1984), were not available in the literature before 1984 . Also, exact tests are now more common due to the recent development of computer power and of the occurrence of fast algorithms. But these exact tests require, in general, count data of genes or genotypes, which can rarely be reconstructed from published frequency data.

\section{How do previous $F_{\text {is }}$ estimators and tests affect our appreciation of heterozygote deficiency?}

The most commonly used $F_{1 s}$ estimator is the quantity $1-H_{o} / H_{e}$ (Table 2), which is the maximum likelihood estimate (MLE) for the 2-allele case (Brown 1970). For more alleles, this quantity is not the MLE and it underestimates heterozygote deficiency (Curie-Cohen 1982). Other $F_{1 s}$ estimators, such as $f_{c}$ (Weir \& Cockerham 1984) or $f_{\gamma}$ (Robertson \& Hill 1984), are used only in 3 recent studies. Apparently most authors were not convinced of the utility of 'a standard set of formulae, clearly derived as estimators for well defined parameters' (Weir \& Cockerham 1984).

All the tests used are concerned with the same null hypothesis, i.e. Hardy-Weinberg equilibrium. However, they do not have the same power with respect to a specific alternative hypothesis $\left(H_{1}\right)$ : their probabilities of rejecting the null hypothesis differ when $H_{1}$ is true. There are various ways to depart from HardyWeinberg equilibrium, and heterozygote excess or deficiency is only one possibility. A departure from 
HWE could be the result of deficiency or excess of some particular genotypes (for example due to selection) without necessarily affecting a global heterozygote deficiency. The exception is the 2-allele case, where any departure from HWE could be explained as a heterozygote excess or deficiency. This is because, with only 2 alleles, gene frequencies and $1 F_{\text {is }}$ parameter completely describe the genotypic composition of a population. There have been repetitive warnings in the literature on the frequent confusion between testing HWE and testing heterozygote deficiency compared to HWE (see e.g. Pamilo \& Varvio-Aho 1984, Lessios 1992). This is particularly true for tests which have a substantial power with respect to other alternative hypotheses, such as the $\mathrm{X}^{2}$-g test, which is widely used in the earlier literature on Mytilus edulis (Table 3).

The $\mathrm{X}^{2}-2$ test is also widely used (Table 3 ). This test uses the formula of Brown (1970), valid for only 2 alleles. Its use when more than 2 alleles are present is incorrect, as the asymptotic variance of $F_{i s}$ is $1 / n(k-1)$. $k$ being the number of alleles, and not $1 / n$ (Curie-Cohen 1982). As the latter quantity is larger than the former, the test using $1 / n$ as the variance of $F_{i s}$ is more conservative. The other tests ( $\mathrm{X}^{2}-\mathrm{h}$ and $f_{T}$-test) are used in a minority of studies (Table 3 )

In conclusion, the most widely used $F_{\text {is }}$ estimator has a tendency to underestimate heterozygote deficiency. Most tests used in the Mytilus edulis literature either have a substantial power with respect to other alterna tive hypotheses to heterozygote deficiency (so that a significant $p$-value does not necessarily indicate a departure of HWE due to a heterozygote deficiency) or are not correctly used. In the latter situation $\left(\mathrm{X}^{2}-2\right.$ test),

Table 12. Measures and tests of heterozygote deficiency for the Pacific American data set (6 populations). Weir \& Cockerham (1984) and Robertson \& Hill (1984) estimators of $F_{15}$ are given for the Aat locus in each sample (respectively $f_{c}$ and $f_{T}$ ). The estimate for all samples is indicated ('A.ll'). Unbiased estimates of exact p-values of the U-score test (Markov chain of 50000 steps for each locus in each population and of 20000 steps for multi-population tests) are given. Bold characters indicate significant $(p<0.05)$ results

\begin{tabular}{|lccc|}
\hline Sample & \multicolumn{2}{c}{ Aat } & Test \\
& $f_{c}$ & $f_{T}$ & \\
\hline Mukilteo & -0.030 & +0.089 & 0.074 \\
Picnic Point & +0.150 & +0.134 & $<2 \times 10^{-5}$ \\
Alki Point & +0.489 & +0.217 & $\mathbf{0 . 0 1 1}$ \\
Seahurst & +0.277 & +0.151 & $\mathbf{0 . 0 0 5}$ \\
Saltwater & -0.036 & -0.013 & 1 \\
Dash Point & +0.097 & +0.140 & $\mathbf{0 . 0 1 9}$ \\
All & +0.162 & & $<5 \times 10^{-5}$ \\
\hline
\end{tabular}

reports of significant heterozygote deficiency are not to be reconsidered, as the incorrect test is more conservative. The existing literature concerning heterozygote deficiency in $M$. edulis (and probably in other marine molluscs as well) provides a conservative figure of the real phenomenon. This is confirmed by the large and significant heterozygote deficiencies present in all data sets analyzed with the same statistical tools (Tables $4 \& 6$ to 12 ).

\section{Influence of the population genetic structure (Wahlund effect)}

Although the random constitution of small and differentiated reproductive groups is an unlikely phenomenon to explain substantial heterozygote deficiency (e.g. Pudovkin \& Zhivotovskii 1980), the various members of the Mytilus edulis complex are genetically differentiated. They do not have a continuous distribution, and they display numerous hybrid or contact zones when they meet. Some complex situations exist: in the British Isles at least 10 hybrid zones between $M$. edulis and $M$. galloprovincialis were identified (Skibinski \& Beardmore 1979, Skibinski et al. 1983, Gosling 1984); on the French Atlantic coast there is also an intercalation of $M$. edulis and $M$. galloprovincialis and hybrids (Coustau et al. 1991, Koehn 1991); M. trossulus and $M$. galloprovincialis are both present along the Pacific coast of North America (plus $M$. edulis near Vancouver, see below), in a complex pattern depending on local ecological differences (Sarver \& Foltz 1993), and these 2 taxa produce a contact zone (they do not hybridize extensively) when they meet (Rawson \& Hillbish 1995); on the eastern North American coast $M$. edulis and $M$. trossulus are both found in a patchy pattern (Varvio et al. 1988, Koehn 1991, Bates \& Innes 1995). For the latter geographic area, heterozygote deficiencies described before the discovery of this situation are best explained by a Wahlund effect, as suspected by Koehn et al. (1976).

The effect of recent extensive introduction of various members of the Mytilus edulis complex (through, e.g., commercial cultures or discharge of ballast water in transport ships) should not be ignored. For example, in the eastern and southern coast of Vancouver island, Canada, all populations of normally pure $M$. trossulus have been recently reported as 'contaminated' by $M$. edulis and M. galloprovincialis (Heath et al. 1995). Whether this phenomenon explains the heterozygote deficiency (Table 12) found in mussels sampled in 1971 and 1972 near Seattle, WA, USA, by Johnson \& Utter (1973), or in other areas, remains to be investigated.

Recently, a secondary intergradation within Mytilus galloprovincialis has been described in Spain follow- 
ing a large sampling effort around the Iberian Peninsula (Sanjuan et al. 1994, 1996, Quesada et al. 1995a, b). But the frequency of such phenomena in other geographic areas is unknown, and it is possible that other similar situations yet to be discovered could account for some reports of heterozygote deficiency.

It is also possible that the species complex Mytilus edulis, in addition to $M$. edulis, $M$. galloprovincialis and $M$. trossulus, contains other members not yet recognized, as suggested by sequences of $18 \mathrm{~S}$ rDNA (Kenchington et al. 1995). If confirmed, the existence of additional sibling species could potentially explain many reports of heterozygote deficiency.

Another possibility is a temporal Wahlund effect, where differentiated cohorts are simultaneously sampled and analyzed. The existence of genetic differences between discrete settlement cohorts of Mytilus edulis has been found (Gosling \& Wilkins 1985), so that this phenomenon could explain some reports of heterozygote deficiency whenever age classes could not be identified. A problem is that cohorts are not necessarily equivalent to size classes, as successive reproductive peaks may occur within a year for species such as $M$. edulis (Seed 1976, Gosling \& Wilkins 1985). In addition, size and age classes are not exactly equivalent even for species showing only 1 annual peak of reproduction (David et al. 1995). In the few studies where age classes could be identified, some report heterozygote deficiency (Koehn \& Gaffney 1984, Gosling \& Wilkins 1985, Zouros et al. 1988) but others do not (Fevolden \& Garner 1986). The absence of congruent ranking of $\hat{F}_{\text {is }}$ across populations for the various loci, for each study or overall (Lap excluded, Table 5), is consistent with a Wahlund effect (spatial or temporal).

\section{Are the loci usually studied under some sort of direct or indirect selection explaining a irequent report of heterozygote deficiency?}

At least for the Lap locus, the answer is clearly positive. The nature of the selection acting at the Lap locus has been the focus of biochemical, physiologica! and populational investigations (Koehn et al. 1980, Moore et al. 1980, Koehn \& Immermann 1981, Koehn \& Siebenaller 1981. Hilbish et al. 1982, Hilbish 1985. Hilbish \& Koehn 1985, Beaumont et al. 1988, 1989), and selective processes can be suspected at least whenever larvae settle in a place where the salinity differs from where they originate. The $\hat{F}_{i s}$ values at the Lap locus are large in all data sets (overall estimate for each data set between 0.08 and 0.16), and these deficits are significant in all data sets (Tables 6 , $9 \& 11$ ), with the exception of the French set. Further information concerning water salinity experienced by larvae before settlement is required to understand this pattern (Table 8 ).

For other loci, there are some hints in the literature that some sort of selection operates in some conditions (e.g. Beaumont et al. 1983, Mallet et al. 1985, Hilbish et al. 1994), although it is never demonstrated as clearly as for the Lap locus. In addition, the intricate geographical mosaic of the various members of the Mytilus edulis complex (Skibinski \& Beardmore 1979, Skibinski et al. 1983, Gosling 1984, Varvio et al. 1988, Coustau et al. 1991. Koehn 1991, McDonald et al. 1991, Sarver \& Foltz 1993, Sanjuan et al. 1994, Bates \& Innes 1995) could introduce a bias, in particular in experiments conducted to show selection on enzymatic loci (Väinölä 1990).

No obvious heterogeneity of $\hat{F}_{l s}$ could be detected, as the median of $\hat{F}_{i s}$ for each locus does not vary significantly across data sets, and the median of $\hat{F}_{i s}$ for each data set does not vary significantly across loci when Lap is excluded. This negative result does not prove that these loci are neutral, as the tests used probably have a low power with respect to alternative hypotheses of some variation of $F_{i s}$ across loci or across geographical areas. More specific tests should be constructed to possibly detect such variation, but this is beyond the scope of the present paper.

The absence of congruent effects across loci is consistent with the possibility that locus-specific factors are involved, and this situation is consistent with 1 or several spatially variable selective processes acting differently at several loci. This situation is also consistent with a mosaic distribution of differentiated populations or sub-species, with loci displaying different or similar gene frequencies across the distribution, thus generating a heterozygote deficiency through a Wahlund effect only for some loci.

\section{Other possible factors}

Some other factors potentially contributing to a heterozygote deficiency have not been thoroughly considered in this paper They include, for example, allele misscoring, aneuploidy or the presence of null alleles. Allele misscoring cannot be ruled out as some loci are sometimes difficult to read, with a heterozygote being more often classified as a homozygote than the reverse (N. Pasteur pers. comm.). Such difficulty is probably variable across loci and laboratories (as all environmental conditions during electrophoresis cannot easily be replicated), and its consequence for the phenomenon of heterozygote deficiency remains to be investigated. It is worth noting that a possible misscoring of a heterozygote to a rare homozygote is unlikely to account for the heterozygote deficiency observed here, 
as removing 2 different homozygotes and replacing them by 2 corresponding heterozygotes (thus keeping the allelic margin constant), for each test, would not have altered the conclusion, except for the locus Est-D in the French data set (details not shown). Aneuploidy has been documented in Mytilus edulis from a polluted area (Dixon 1982), but its significance in explaining heterozygote deficiency remains unclear. In addition, in the oyster Crassostrea gigas, where this problem has been thoroughly studied, aneuploidy has been found to be an unlikely explanation for this phenomenon (Zouros et al. 1996). The presence of null alleles at isozymic loci have been studied for Mytilus, and their low observed frequency in natural populations or during crosses cannot account for the level of heterozygote deficiency usually found (Mallet et al. 1985, Beaumont 1991, Gardner 1992).

\section{CONCLUSION}

Heterozygote deficiency is not clearly described in the literature, due to the variety of species studied, the various qualities of the $F_{i s}$ estimators used, and the pertinence of the different statistical tests applied. When several data sets are analyzed or re-analyzed using the same estimators and tests, the heterozygote deficiency still persists for the species complex Mytilus edulis. In this species complex, 2 factors are difficult to control: the spatial and temporal genetic differentiation and selection acting (directly or indirectly) on the marker loci. The latter is possible, but small variation of $F_{\text {is }}$ across loci or geographical areas cannot be detected at present due to a lack of specific and powerful tests in this domain; hence the possibility that selection operates constantly to maintain the genetic identity of each taxon adapted to local conditions, despite high dispersal potential (Gardner 1996), cannot be excluded. Spatial and temporal genetic differentiation cannot be discounted due to the complex genetic structure found at various geographical scales and the continuous discovery of hybrid or contact zones, secondary intergradations or perhaps additional sibling species within the $M$. edulis species complex. This geographically or temporally complex pattern could explain some reports of heterozygote deficiency in the $M$. edulis species complex. In particular the temporal Wahlund effect has not been extensively studied, and its importance remains to be investigated in Mytilus as well as in other molluscs since the existence of genetically differentiated cohorts or complex spatial population dynamics has been reported in other marine molluscs (e.g. Johnson \& Black 1984, Borsa et al. 1991, Lewis \& Thorpe 1994, David et al. 1996).
Due to the intricate situation encountered with Mytilus edulis, detailed studies similar to the present study are required for other species before any general conclusion can be drawn. Interesting results should come out from the comparison of allozyme loci and other markers such as anonymous DNA fragments or anonymous genes, but it is too early to draw general conclusions from the few recent papers published in this area (e. g. Pogson \& Zouros 1994, Hare et al. 1996), especially as these have opposing conclusions.

As heterozygote deficiency is also present in other species such as self-incompatible or essentially outbreeding plants (Levin 1978, Cuguen et al. 1988), it is likely that there is no unique explanation for the problem of heterozygote deficiency in marine bivalves (see e.g. Gaffney et al. 1990) and in other organisms, and it is not excluded that species-specific, locus-specific or population-specific explanations are to be sought.

Acknowledgements. We are very grateful to P. M. Gaffney E. M. Gosling for sending data upon request and to $P$. Borsa C. Chevillon, P. David, P. Jarne, N. Pasteur, A. I. Pudovkin, R. Väinölä and 2 anonymous reviewers for helpful comments Research was supported in part by the Service Commun de Systematique, Montpellier and IFREMER. Part of this work was performed during sabbatical leave by M.R. at P. Pamilo laboratory, Uppsala University. This is paper no. 97.084 of the Institut des Sciences de l'Evolution

\section{LITERATURE CITED}

Ahmad M, Hedrick PW (1985) Electrophoretic variation in the common mussel, Mytilus edulis: random association of alleles at different loci. Heredity 55:47-51

Bates JA, Innes DJ (1995) Genetic variation among populations of Mytilus spp. in eastern Newfoundland. Mar Biol $124: 417-424$

Beaumont AR (1991) Genetic studies of laboratory reared mussels, Mytilus edulis: heterozygote deficiencies, heterozygosity and growth. Biol J Linn Soc 44:273-285

Beaumont AR, Beveridge CM, Barnet EA, Budd MD (1989) Genetic studies of laboratory reared Mytilus edulis. II. Selection at the leucine amino peptidase (Lap) locus. Heredity 62:169-176

Beaumont AR, Beveridge CM, Barnet EA, Budd MD, SmythChamosa $M$ (1988) Genetic studies of laboratory reared Mytilus edulis. I. Genotype specific selection in relation to salinity. Heredity 61:389-400

Beaumont AR, Beveridge CM, Budd MD (1983) Selection and heterozygosity within single families of the mussel Mytilus edulis (L.). Mar Biol Lett 4:151-161

Borsa P, Zainuri M, Delay B (1991) Heterozygote deficiency and population structure in the bivalve Ruditapes decussatus. Heredity $66: 1-8$

Boyer JF (1974) Clinal and size-dependent variation at the Lap locus in Mytilus edulis. Biol Bull (Woods Hole) 147: 535-549

Brown AHD (1970) The estimation of Wright's fixation index from genotypic frequencies. Genetica 41:399-406

Coustau C, Renaud F, Delay B (1991) Genetic characterization of the hybridization between Mytilus edulis and $M$. gallo- 
provincialis on the Atlantic coast of France. Mar Biol 111 87-93

Cuquen J, Merzeau D, Thiebaut B (1988) Genetic structure of the European beech stands (Fagus sylvatica L.): F-statistics and importance of mating system characteristics in their evolution. Heredity 60:91-100

Curie-Cohen $M$ (1982) Estimates of inbreeding in a natural population: a comparison of sampling properties. Genetics 100:339-358

David P, Berthou P, Noel P, Jarne P (1996) Spatially structured recruitment and population dynamics in a marine bivalve: Spisula ovalis. Oecologia 111:331-340

David P, Delay B, Berthou P, Jarne P (1995) Alternative models for allozyme-associated heterosis in the marine bivalve Spisula ovalis. Genetics 139:1719-1726

Diehl WJ, Gaffney PM, McDonald JH, Koehn RK (1985) Relationship between weight-standardized oxygen consumption and multiple-locus heterozygosity in the mussel, Mytilus edulis. In: Gibbs PE (ed) Proc 19th Eur Mar Biol Symp. Cambridge University Press, Cambridge, p $529-534$

Dixon DR (1982) Aneuploidy in mussel embryos (Mytilus edulis L.) originating from a polluted dock. Mar Biol Lett 3 : $155-161$

Fairbrother JE, Beaumont AR (1993) Heterozygote deficiencies in a cohort of newly settled Mytilus edulis spat. J Mar Biol Assoc UK 73:647-653

Fevolden SE, Garner SP (1986) Population genetics of Mytilus edulis (L.) from Oslofjorden, Norway, in oil-polluted and non oil-polluted water. Sarsia 71:247-257

Fisher RA (1970) Statistical methods for research workers. Olivier and Boyd, Edinburgh

Foltz DW (1986) Null alleles as a possible cause of heterozygote deficiencies in the oyster Crassostrea virginica and other bivalves. Evolution 40:869-870

Gaffney PM (1990) Enzyme heterozygosity, growth rate, and viability in Mytilus edulis: another look. Evolution 44 $201-21.0$

Gaffney PM, Scott TM, Koehn RK, Diehl WJ (1990) Interrelationships of heterozygosity, growth rate and heterozygote deficiencies in the coot clam, Mulinia lateralis. Genetics 124:687-699

Gardner JPA (1992) Null alleles and heterozygote deficiencies among mussels (Mytilus edulis and M. galloprovinciallis) of two sympatric populations. Malacologia 34 : 99-106

Gardner JPA (1996) The Mytilus edulis species complex in southwest England: effects of hybridization and introgression upon interlocus associations and morphometric variation. Mar Biol 125:385-399

Gentili MR, Beaumont AR (1988) Environmental stress, heterozygosity, and growth rate in Mytilus edulis L. J Exp Mar Biol Ecol 120:145-153

Gosling EM (1984) The systematic status of Mytilus galloprovincialis in western Europe: a review. Malacologia 25: $551-568$

Gosling EM (1989) Genetic heterozygosity and growth rate in a cohort of Mytilus edulis from the Irish coast. Mar Biol $100: 211-215$

Gosling EM, Wilkins NP (1985) Genetics of settling cohorts of Mytilus edulis (L.): preliminary observations. Aquaculture 44:115-123

Guo SW. Thompson E (1992) Performing the exact test of Hardy-Weinberg proportion for multiple alleles. Biometrics 48:361-372

Hare MP, Karl SA, Avise JC (1996) Anonymous nuclear DNA markers in the American oyster and their implications for the heterozygote deficiency phenomenon in marine bivalves. Mol Biol Evol 13:334-345

Heath DD, Rawson PD, Hilbish TJ (1995) PCR-based nuclear markers identify alien blue mussel (Mytilus spp.) genotypes on the west coast of Canada. Can J Fish Aquat Sci 52:2621-2627

Hilbish TJ (1985) Demographic and temporal structure of an allele frequency cline in the mussel Mytilus edulis. Mar Biol 86:163-171

Hilbish TJ, Bayne BL, Day A (1994) Genetics of physiological differentiation within the marine mussel genus Mytilus Evolution 48:267-286

Hilbish TJ, Deaton LE, Koehn RK (1982) Effect of an allozyme polymorphism on regulation of cell volume. Nature 298 $688-689$

Hilbish TJ, Koehn RK (1985) Exclusion of the role of secondary contact in an allele frequency cline in the mussel Mytilus edulis. Evolution 39:432-443

Johnson AG, Utter FM (1973) Electrophoretic variants of aspartate aminotransferase of the bay mussel, Mytilus edulis (Linnaeus, 1758). Comp Biochem Physiol 44B 317-323

Johnson MS, Black R (1984) Pattern beneath the chaos: the effect of recruitment on genetic patchiness in an intertidal limpet. Evolution 38:1371-1383

Kenchington E, Landry D, Bird CJ (1995) Comparison of taxa of the mussel Mytilus (Bivalvia) by analysis of the nuclear small-subunit rRNA gene sequence. Can J Fish Aquat Sci 52:2613-2620

Koehn RK (1991) The genetics and taxonomy of species in the genus Mytilus. Aquaculture 94:125-145

Koehn RK, Gaffney PM (1984) Genetic heterozygosity and growth rate in Mytilus edulis. Mar Biol 82:1-7

Koehn RK, Immermann FW (1981) Biochemical studies of aminopeptidase polymorphism in Mytilus edulis. I Dependence of enzyme activity on season, tissue, and genotype. Biochem Genet 19:1115-1142

Koehn RK, Milkman R, Mitton JB (1976) Population genetic of marine pelecypods. IV Selection, migration and genetic differentiation in the blue mussel Mytilus edulis. Evolution $30: 2-32$

Koehn RK, Mitton JB (1972) Population genetics of marine pelecypods. I. Ecological heterogeneity and evolutionary strategy at an enzyme locus. Am Nat 106:47-56

Koehn RK, Newell RIE, Immermann F (1980) Maintenance of an aminopeptidase allele frequency cline by natural selection. Proc Natl Acad Sci USA 77:5385-5389

Koehn RK, Siebenaller JF (1981) Biochemical studies of aminopeptidase polymorphism in Mytilus edulis. II. Dependence of reaction rate on physical factors and enzyme concentration. Biochem Genet 19:1143-1162

Lassen HH. Turano FJ (1978) Clinal variation and heterozygote deficit at the Lap-locus in Mytilus edulis. Mar Biol 49 : $245-254$

Lessios HA (1992) Testing electrophoretic data for agreement with Hardy-Weinberg expectations. Mar Biol 112:517-523

Levene $H$ (1949) On a matching problem in genetics. Ann Math Stat 20:91-94

Levin DA (1978) Genetic variation in annual Phlox: selfcompatible versus self-incompatible species. Evolution 32 : 245-263

Lewis RI, Thorpe JP (1994) Temporal stability of gene frequencies within genetically heterogeneous populations of the queen scallop Aequipecten (Chlamys) opercularis. Mar Biol 121:117-126

Li CC, Horvitz DG (1953) Some methods of estimating the inbreeding coefficient. Am J Hum Genet 5:107-117 
Louis EJ, Dempster ER (1987) An exact test for Hardy-Weinberg and multiple alleles. Biometrics 43:805-811

Mallet AL, Zouros E, Gartner-Keplay KE, Freeman KR, Dickie LM (1985) Larval viability and heterozygote deficiency in populations of marine bivalves: evidence from pair matings of mussels. Mar Biol 87:165-172

McDonald JH, Seed R, Koehn RK (1991) Allozymes and morphometric characters of three species of Mytilus in the Northern and Southern Hemispheres. Mar Biol 111: $323-333$

Milkman R, Beaty LD (1970) Large-scale electrophoretic studies of allelic variation in Mytilus edulis. Biol Bull (Woods Hole) 139:430

Mitton JB, Koehn R, Prout T (1973) Population genetics of marine pelecypods. III. Epistasis between functionally related isoenzymes of Mytilus edulis. Genetics 73:473-496

Moore MN, Koehn RK, Bayne B (1980) Leucine aminopeptidase (aminopeptidase-I), $\mathrm{N}$-acetyl-b-hexosaminidase and lysosomes in the mussel, Mytilus edulis L., in response to salinity changes. J Exp Biol 214:239-249

Pamilo P, Varvio-Aho S (1984) Testing genotype frequencies and heterozygosities. Mar Biol 79:99-100

Pogson GH, Zouros E (1994) Allozyme and RFLP heterozygosities as correlates of growth rate in the scallop Placopecten magellanicus: a test of the associative overdominance hypothesis. Genetics 137:221-231

Pudovkin AI, Zhivotovskii LA (1980) Deficit of heterozygotes in populations of marine benthic invertebrates. Soviet $J$ Mar Biol 6:286-289

Quesada H, Beynon CM, Skibinski DOF (1995a) A mitochondrial DNA discontinuity in the mussel Mytilus galloprovincialis Lmk: pleistocene vicariance biogeography and secondary intergradation. Mol Biol Evol 12:521-524

Quesada H, Zapata C, Alvarez G (1995b) A multilocus allozyme discontinuity in the mussel Mytilus galloprovincialis: the interaction of ecological and life-history factors. Mar Ecol Prog Ser 116:99-115

Rawson PD, Hilbish TJ (1995) Distribution of male and female mtDNA lineages in populations of blue mussels, Mytilus trossulus and $M$. galloprovincialis, along the Pacific coast of North America. Mar Biol 124:245-250

Raymond M, Rousset F (1995) Genepop (version 1.2), population genetics software for exact tests and ecumenicism. J Hered 86:248-249

Robertson A, Hill WG (1984) Deviation from Hardy-Weinberg proportions: sampling variances and use in estimation of inbreeding coefficients. Genetics 107:703-718

Rousset F, Raymond M (1995) Testing heterozygote excess and deficiency. Genetics 140:1413-1419

Sanjuan A, Comesana AS, De Carlos A (1996) Macrogeographic differentiation by mtDNA restriction site analysis in the S.W. european Mytilus galloprovincialis Lmk. J Exp Mar Biol Ecol 198:89-100

Sanjuan A, Quesada H, Zapata C, Alvarez G (1990) On the occurrence of Mytilus galloprovincialis Lmk. on the N.W. coast of the Iberian Peninsula. J Exp Mar Biol Ecol 143: $1-14$

Sanjuan A, Zapata C, Alvarez G (1994) Mytilus galloprovincialis and Mytilus edulis on the coast of the Iberian Penin-

This article was submitted to the editor sula. Mar Ecol Prog Ser 113:131-146

Sarver SK, Foltz DW (1993) Genetic population structure of a species' complex of blue mussels (Mytilus spp.). Mar Biol $117: 105-112$

Seed R (1976) Ecology. In: Bayne BL (ed) Marine mussels: their ecology and physiology. Cambridge University Press, Cambridge, p 13-65

Siegel S, Castellan N Jr (1988) Nonparametric statistics for the behavioral sciences. McGraw-Hill, New York

Singh SM, Green RH (1984) Excess of allozyme homozygosity in marine molluscs and its possible biological significance. Malacologia 25:569-581

Skibinski DOF (1983) Natural selection in hybrid mussel populations. In: Oxford GS, Rollinson D (eds) Protein polymorphism: adaptative and taxonomic significance. Academic Press, London, p 283-298

Skibinski DOF, Beardmore JA (1979) A genetic study of intergradation between Mytilus edulis and Mytilus galloprovincialis. Experientia (Basel) 35:1442-1444

Skibinski DOF, Beardmore JA, Ahmad M (1978) Genetic aids to the study of closely related taxa of the genus Mytilus. In: Battaglia B, Beardmore JA (eds) Marine organisms: genetics, ecology and evolution. Plenum Press, New York, p $469-485$

Skibinski DOF, Beardmore JA, Cross TF (1983) Aspects of the population genetics of Mytilus (Mytilidae; Mollusca) in the British Isles. Biol J Linn Soc 19:137-183

Thomas $F$ (1993) Structuration génétique de populations de bivalves (Mytilus) des côtes françaises (Atlantique et Méditerranée) [Population genetic structure of bivalves ( $M y-$ tilus) from France (Atlantic and Mediterranean)]. Diplome d'Etudes Approfondies, Université de Montpellier II

Väinölä R (1985) Sinisimpukan geenifrekvenssivaihtelu Itämeressä (Gene frequency variation in Baltic mussel populations). MSc thesis, University of Helsinki

Väinölä R (1990) Allozyme differentiation between Baltic and North sea Mytilus populations: a reassessment of evidence from transportations. Mar Ecol Prog Ser 67:305-308

Väinölä R, Hvilsom MM (1991) Genetic divergence and a hybrid zone between Baltic and North Sea Mytilus populations (Mytilidae: Mollusca). Biol J Linn Soc 43:127-148

Varvio SL, Koehn RK, Väinolä R (1988) Evolutionary genetics of the Mytilus edulis complex in the North Atlantic region. Mar Biol 98:51-60

Wahlund T (1928) Zusammensetzung von Populationen und Korrelationserscheinungen vom Standpunkt der Vererbungslehre aus betrachtet. Hereditas (Lund) 11:65-106

Weir BS, Cockerham CC (1984) Estimating $F$-statistics for the analysis of population structure. Evolution 38:1358-1370

Zouros E, Foltz DW (1984) Possible explanations of heterozygote deficiency in bivalve molluscs. Malacologia 25: 583-591

Zouros E, Romero-Dorey M, Mallet AL (1988) Heterozygosity and growth in marine bivalves: further data and possible explanations. Evolution 42:1331-1341

Zouros E, Thiriot-Quievreux C, Kotoulas G (1996) The negative correlation between somatic aneuploidy and growth in the oyster Crassostrea gigas and implications for the effect of induced polyploidization. Genet Res 68:109-116

Manuscript received: February 3, 1997

Revised version accepted: July 11, 1997 